\title{
Hypericin fluorescence kinetics in the presence of low density lipoproteins: study on quail CAM assay for topical delivery
}

\author{
Monika Buríková1,2, Boris Bilč́k ${ }^{1}$, Mariana Máčajová ${ }^{1}$, Pavel Výboh ${ }^{1}$, Jozef Bizik², \\ Anton Mateašík ${ }^{3}$, Pavol Miškovskýy ${ }^{4,6}$ and Ivan Čavarga ${ }^{1,5}$ \\ ${ }^{1}$ Institute of Animal Biochemistry and Genetics, SAS, Ivanka pri Dunaji, Slovak Republic \\ ${ }^{2}$ Cancer Research Institute, BMC, SAS, Bratislava, Slovak Republic \\ ${ }^{3}$ International Laser Centre, Department of Biophotonics, Bratislava, Slovak Republic \\ ${ }^{4}$ Center for Interdisciplinary Biosciences, Faculty of Sciences, P. J. Šafárik University, Košice, Slovak Republic \\ ${ }^{5}$ St. Elisabeth Oncological Institute, Bratislava, Slovak Republic \\ ${ }^{6}$ SAFTRA photonics Ltd, Košice, Slovak Republic
}

\begin{abstract}
There has been increasing interest in fluorescence-based imaging techniques in clinical practice, with the aim to detect and visualize the tumour configuration and the border with healthy tissue. Strong photodynamic activity of hypericin (Hyp) can be improved by various molecular transport systems (e.g. LDL). Our aim was to examine pharmacokinetics of Hyp in the presence of LDL particles on ex ovo chorioallantoic membrane (CAM) of Japanese quail with implanted TE1 tumour spheroids (human squamocellular carcinoma). Spheroids were implanted on CAM surface on embryonal day 7 and after 24 hours formulations of free Hyp and Hyp:LDL 100:1 and 200:1 were topically applied. All experimental formulations in the fluorescent image very well visualized the tumour spheroid position, with gradual increase of fluorescence intensity in 6-h observation period. LDL transportation system exhibited clear superiority in fluorescence pharmacokinetics than free Hyp formulation by increasing tumour-normal difference. Our experimental results confirm that Hyp and Hyp:LDL complex is potent fluorophore for photodynamic diagnosis of squamocellular carcinoma.
\end{abstract}

Key words: Hypericin — LDL - CAM — Photodynamic diagnosis - Japanese quail

Abbreviations: CAM, chorioallantoic membrane; Hyp, hypericin; LDL, low-density lipoprotein; PDD, photodynamic diagnosis; PS, photosensitizer; SCC, squamous cell carcinoma.

\section{Introduction}

Diagnostic potential of tissue fluorescence is intensively exploited in experimental and clinical practice. Fluorescence diagnostic imaging visualizes lesions through specific tissue fluorescence caused by endogenous fluorescence (autofluorescence), or exogenous, drug-induced fluorescence. Photodynamic diagnosis (PDD) uses photosensitizing agents - photosensitizers (PS) with specific fluorescent properties to

Correspondence to: Boris Bilčík, Institute of Animal Biochemistry and Genetics, Slovak Academy of Sciences, Moyzesova 61, 90028 Ivanka pri Dunaji, Slovak Republic

E-mail: Boris.Bilcik@savba.sk target cancer detection. This approach has been established in several surgical and endoscopic methods (Leunig et al. 1996; Betz et al. 2002; Zheng et al. 2004; Olivo et al. 2011). In clinical practice, early lesions of oral and bladder cancer are hardly visible through subtle and flat configuration and it is difficult to distinguish border between the tumour and healthy tissue. PDD is using fluorescence endoscopy system to visualize neoplastic lesions after topical or systemic application of a tumour-selective PS. Exact demarcation of tumour margins using this technique could contribute to optimum results in surgical excision and reconstruction (Olivo et al. 2011).

The predominant type (over 90\%) of tumours in the oral cavity is squamous cell carcinoma (SCC) (Neville et al. 2002; 
Kawczyk-Krupka et al. 2012). Usual diagnostic approach is white light endoscopy, followed by histopathological examination of biopsy tissue. Oral lesions, however, tend to be flat, difficult to distinguish benign from malignant and to determine the margins of lesions (Thong et al. 2009). Although biopsy procedures are generally safe, fluorescence diagnostic imaging has a potential to reduce unnecessary tissue biopsies.

In the last years, number of papers have analysed the chemical and photophysical as well as photobiological properties of hypericin (Hyp). This substance is extracted from a plant species Hypericum perforatum (St. John'sWort). Strong photodynamic activity of Hyp and consequently its fluorescence phenomenon depends on photochemical and photophysical properties which are characterized by spectral bands with absorption maxima at around 540 and $590 \mathrm{~nm}$, and fluorescence maxima at around 590 and $640 \mathrm{~nm}$ respectively (Miskovsky et al. 2002; Olivo et al. 2011). Hyp has relatively high quantum yield of fluorescence and low photobleaching characteristics compared to some other photosensitizers (Kiesslich et al. 2006).

Hyp has low systemic toxicity and usually accumulates in malignant tumours. Illumination with visible light induces photophysical reactions such as fluorescent light making this process an interesting candidate as a diagnostic tool (Kubin et al. 2008).

Hyp is a lipophilic substance that forms aggregates not soluble in aqueous solutions (Olivo et al. 2011). The cellular uptake of Hyp is mainly by diffusion, but membraneassociated translocation processes may also contribute to the cellular uptake (Thomas et al. 1992).

In order to overcome many biophysical, and biomedical barriers in relation to successful delivery of anticancer drugs, including photosensitizers like Hyp, several types of nanocarriers such as liposomes, dendrimers, polymeric micelles, carbon nanotubes, polymer-drug conjugates, and nanoparticles (polymeric, magnetic, or solid-lipid nanoparticles) have been developed (Debele et al. 2015). Although these systems have promising potential in photosensitizer delivery, their impact on cells and tissues can lead to a wide range of adverse effects and several safety aspects associated with the introduction of these delivery systems to a complex metabolic environment have to be taken into account (Chouikrat 2012; Francois 2012; Búzová 2013).

Strong association between Hyp and serum constituents such as bovine serum albumin and low-density lipoprotein (LDL) and the uptake could be demonstrated to occur via endocytotic internalization and pinocytosis, respectively. Therefore, the membrane-associated mechanism of cellular internalization of Hyp strongly depends on the context of administration (Siboni et al. 2002; Kiesslich et al. 2006). LDL is the major transporter of cholesterol in the plasma used for cell growth and membrane repair. Tumour cells generally have high cholesterol requirements because of their rapid growth (Nikanjam et al. 2007). Upon binding to LDL receptors that interact with the protein moiety (apoB) of LDL particles, LDL is internalized via endocytosis, moved into the lysosome where the particle is degraded (Goldstein et al. 1985). LDL could be a promising delivery system for hydrophobic antitumour drugs which could play the key role for the specific targeting the photosensitizers into the tumour cells (Kascakova et al. 2008).

Interest in replacing the mammalian model for drug testing is still very actual. Avian chorioallantoic membrane (CAM) has been used for the study of tumour angiogenesis and antivascular therapy. More frequent is chicken CAM model, however, Japanese quail (Coturnix japonica) CAM has also been successfully used (Vargas et al. 2007; Čavarga et al. 2014; Nowak-Sliwinska et al. 2014). The CAM contains primarily type IV collagen, similar to the basement membrane of human oral epithelium (Rowe et al. 2009). Grafted tumours on the CAM surface have similar characteristics as the tumours grown in mammalian models, with the additional advantage that the setup of the CAM for cancer studies is faster (Vargas et al. 2007). Long-term evaluations, however, are not feasible because of limited time the quail embryo can survive under ex ovo conditions.

The CAM model has many advantages for tumourigenesis study: the chick embryo system is naturally immunodeficient, hence may accept xenotransplantation from tumours (Xiao et al. 2015) and the model is cost- and time-efficient. The well-vascularized membrane is easily accessible for manipulation and tumour proliferation and invasion is easier to examine. CAM model has been used in breast, bladder, prostate, ovarian and skin cancer for estimating the dissemination and angiogenic potential of cancer cells (Kunzi-Rapp et al. 2001; Lokman et al. 2012; Bush et al. 2013; Liu et al. 2013). CAM model is also advantageous for PDD and for the evaluation PS because of the transparency of its superficial layers. Photodynamic effects can be monitored in real-time, in individual blood vessels (Vargas et al. 2007; Buzzá et al. 2014).

Hyp exhibits high tumour selectivity, however, mechanism of its cellular uptake is not fully understood (Olivo et al. 2012a). Three-dimensional culture systems such as multicellular spheroid clusters are suitable model mimicking tumour nodules and useful tool for the development and testing of anticancer photodynamic therapy regimens (Evans 2015). Studies of bladder cell carcinoma using a spheroid model pointed to the selective uptake Hyp due to the loss in intercellular adhesion in spheroids caused by the reduced expression of a transmembrane adhesion protein E-cadherin (Huygens et al. 2005). Photodynamic effect of Hyp in an ex ovo quail CAM was recently evaluated by Čavarga et al. (2014). 
We anticipate that the use of Hyp-based fluorescence endoscopy can improve the sensitivity and specificity of oral cancer diagnosis compared with white light imaging alone, by providing an enhanced contrast between the lesion and surrounding normal tissue. Therefore, in this study we analyse fluorescence kinetics of Hyp and Hyp/LDL complex after topical application in ex ovo quail CAM assay with grafted TE1 human squamocellular carcinoma spheroids.

\section{Material and Methods}

\section{Preparation of Hyp and LDL formulation}

The stock solution of Hyp (1,3,4,6,8,13-hexahydroxy-10,11dimethylphenanthro [1,10,9,8-opqra]perylene-7,14-dione, Calbiochem, USA) $\left(45 \times 10^{-3} \mathrm{M}\right)$ was prepared by dissolving Hyp in $100 \%$ DMSO (Sigma, USA) and kept in the dark at $4^{\circ} \mathrm{C}$. Working concentration of Hyp ( $2 \mu \mathrm{g} / \mathrm{g}$ of embryo) was prepared immediately prior to the experiment. Average weight of embryos at ED7 was $0.6 \mathrm{~g}$, therefore applied amount was $1.2 \mu \mathrm{g} \mathrm{Hyp} / 30 \mu \mathrm{l}$ PBS $(79 \mu \mathrm{M})$ with $0.17 \%$ DMSO.

The stock solution of LDL $\left(1.04 \times 10^{-5} \mathrm{M}\right.$, Merck, Germany) was kept at $4^{\circ} \mathrm{C}$. The Hyp-LDL formulation used in experiments was prepared by mixing appropriate volumes of LDL and Hyp stock solutions in PBS at pH 7.4. The final quantity of DMSO in all Hyp-LDL solution was $0.17 \%$. The concentration of Hyp was kept constant $(79 \mu \mathrm{M})$ and LDL concentration varied. Final concentration of LDL in Hyp-LDL formulation was $0.39 \mu \mathrm{M}$ for 100:1 Hyp:LDL ratio and $0.79 \mu \mathrm{M}$ for 200:1. This formulation was stored for $2 \mathrm{~h}$ in the dark at room temperature for stabilization before administration.

\section{Fluorescence and absorbance spectroscopy measurements}

Spectra were recorded at room temperature by Spectrofluorometer FluoroLog-3 (Horiba Jobin Yvon, Japan), $\left(\lambda_{\text {exc }}=\right.$ $\left.540 \mathrm{~nm}, \lambda_{\text {emis }}=575 \mathrm{~nm}\right)$. Spectra for Hyp and Hyp:LDL (100:1, 200:1) formulation were measured after $2 \mathrm{~h}$ stabilization period and analysed by Origin 6.0 (OriginLab, USA).

\section{Quail CAM in vivo model}

Fertilized Japanese quail (Coturnix japonica) eggs were incubated in a forced draught incubator at $37^{\circ} \mathrm{C}$ and $50-60 \%$ relative humidity. To prepare in vivo culture, the surface of the eggs at embryonic development day 3 (ED3) was wiped with $70 \%$ ethanol in a sterile laminar flow hood. The eggs were opened and the embryos transferred into six-well tissue culture plates (TPP, Switzerland) and returned to humidified incubator for the next 4 days (Parsons-Wingerter et al. 2000).

\section{Spheroid preparation}

Human esophageal squamous cell carcinoma (TE1) spheroids were cultured in DMEM (PAN-Biotech, Germany) supplemented with $10 \%$ fetal bovine serum (PAN-Biotech, Germany), $100 \mu \mathrm{g} / \mathrm{ml}$ streptomycin, and $100 \mathrm{U} / \mathrm{ml}$ penicillin and were used at passages 5-15. U-bottom 96-well plates (Costar, USA) were treated with $0.8 \%$ LE agarose (BioWhittaker, USA) prepared in sterile water to form a thin layer of nonadhesive surface. To initiate spheroid formation, $250 \mu \mathrm{l}$ aliquots (500 cells/well) were seeded into individual wells and the plates were incubated at $37^{\circ} \mathrm{C}$ in $5 \% \mathrm{CO}_{2}$ atmosphere for next 3 to 5 weeks.

\section{Tumour spheroid implantation}

TE1 spheroid implantation was performed on ED7 under sterile conditions. Silicone ring $(6 \mathrm{~mm})$ was positioned on CAM surface avoiding major blood vessels and 5 to 15 spheroids $(300-500 \mu \mathrm{m})$ were placed within the ring. Successful implantation is observed when the tumour spheroid is engulfed by the CAM (typically 1 day post-implantation). At this stage the model is ready for use in experimental procedure.

\section{Topical pharmacokinetics of Hyp and Hyp:LDL}

24 hours after spheroid implantation (ED8), Hyp and Hyp:LDL 100:1 and 200:1 was topically applied at a dose of $2 \mu \mathrm{g} / \mathrm{g}$ embryo, that is $79 \mu \mathrm{M}$ in PBS with $0.17 \%$ DMSO. Fluorescence intensity in CAM tissue and spheroids was recorded using a digital camera (Canon EOS 5D II with Canon MP-E 65mm, Japan) in 1 hour intervals up to 6 hours after administration. The CAMs were illuminated using either white light (ring flash Canon MR-14EX, Japan) or by blue excitation light (custom made circular blue LED light, $405 \mathrm{~nm}$ ). Subsequent image processing was performed with the ImageJ software (Abramoff et al. 2004).

\section{Statistics}

Two way ANOVA with factors time after administration (0-6 hours) and treatment (Hyp, Hyp:LDL 100:1 and 200:1, respectively), followed by Holm-Sidak post hoc test (SigmaPlot 12, USA) was used.

\section{Results}

An indicator of biological activity of Hyp is fluorescence phenomenon. Only the monomeric form of Hyp exhibits fluorescence emission and so may participate in photodynamic reaction (Mikeš et al. 2011). Prepared Hyp for- 

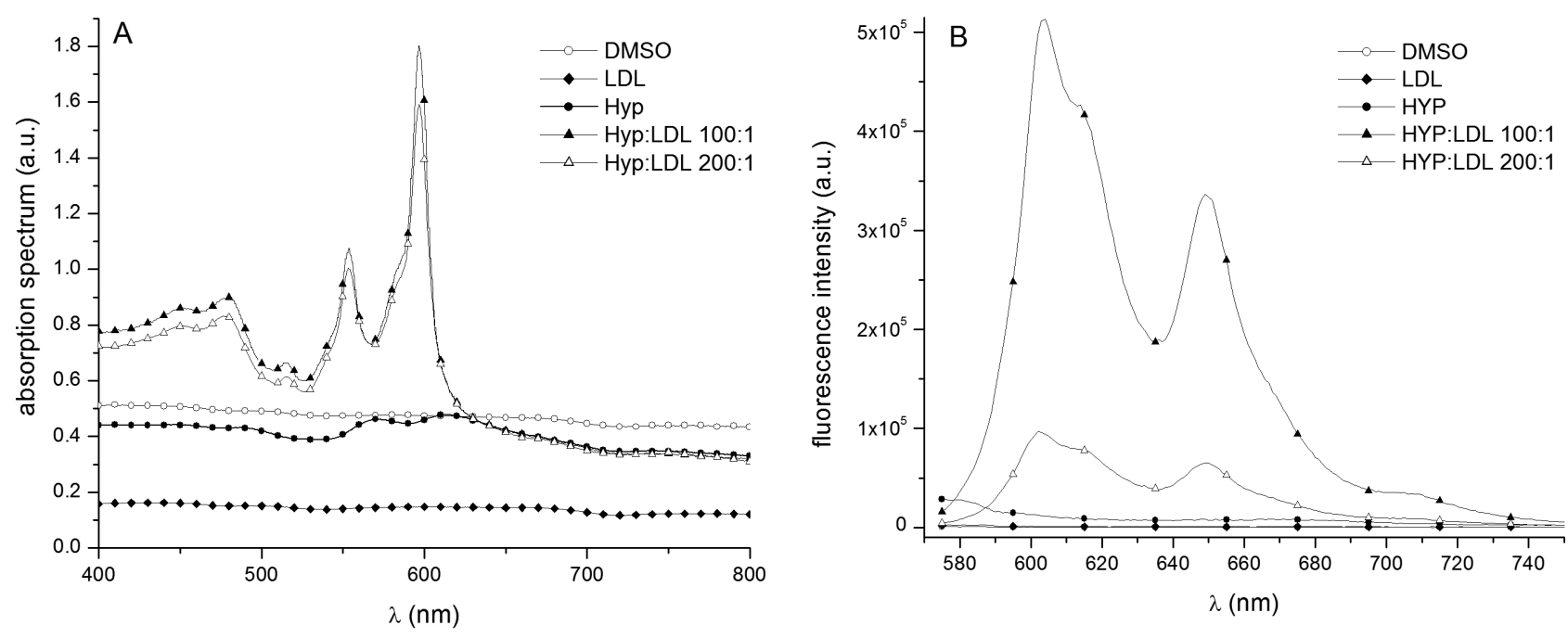

Figure 1. Absorption spectrum (A) and fluorescence spectrum (B) of 79 $\mu \mathrm{M}$ Hyp, Hyp:LDL 100:1 and 200:1, 0.395 $\mu$ M LDL and 0.17\% $\operatorname{DMSO}\left(\lambda_{\mathrm{exc}}=540 \mathrm{~nm}, \lambda_{\mathrm{emis}}=575 \mathrm{~nm}\right)$.

mulation was initially analysed spectroscopically in vitro. Absorption spectrum Hyp:LDL presents typical range of the Hyp with max values at 550 and 596 nm (Fig. 1A). Absorbance spectral curves for Hyp:LDL complex 100:1 and 200:1 did not differ. On the other hand, free Hyp in 0.1\% DMSO shows strong reduction in absorbance which indicates Hyp aggregation in this environment. A similar pattern of changes in the emission spectrum were presented in other spectral

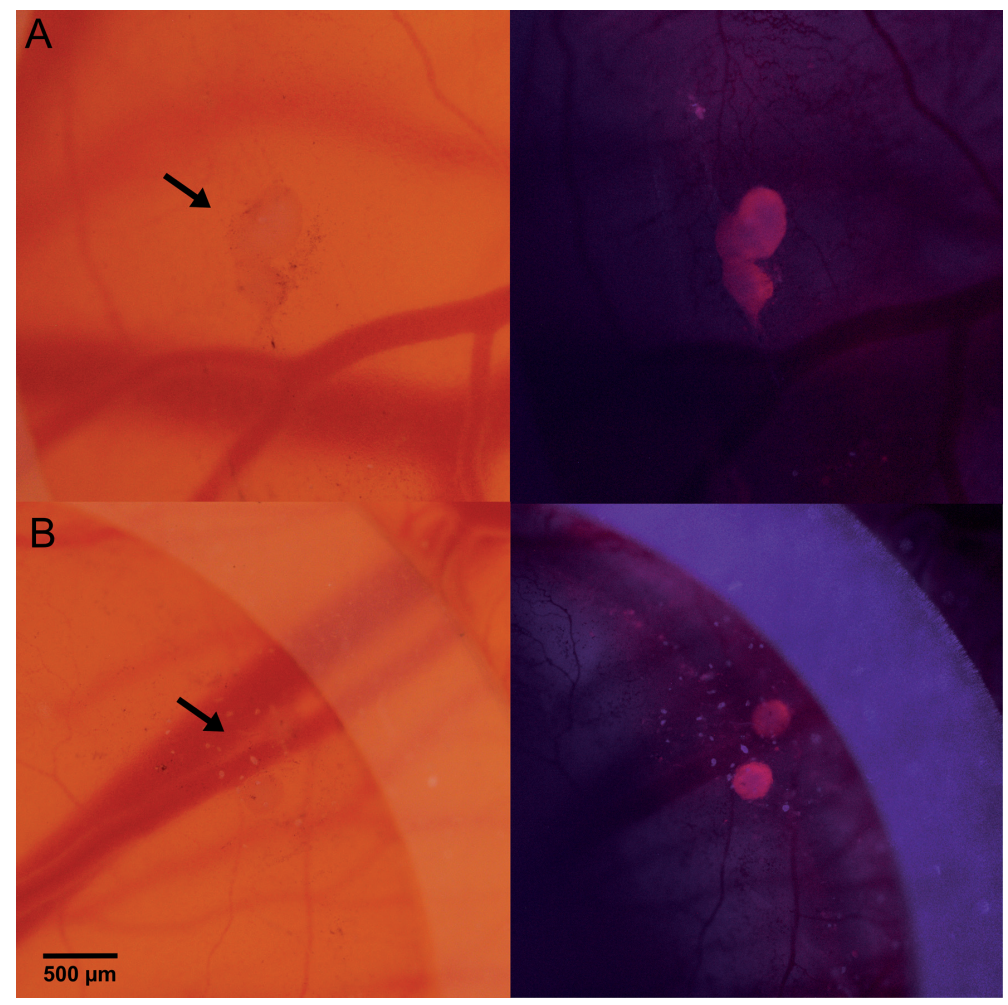

Figure 2. Close-up of spheroid cluster (A) and two single spheroids (B) on CAM surface in white and blue excitation light $6 \mathrm{~h}$ after application Hyp:LDL 200:1. 
analysis (Fig. 1B), where free Hyp itself exhibits very low fluorescence emission. The complex of Hyp:LDL produces a higher fluorescence intensity and aggregation of Hyp in the aqueous medium does not affect the incorporation of Hyp into the LDL particles.

The photosensitizers used in photodynamic diagnosis are expected to be taken up selectively by the tumour, thus visualizing is the area of interest. Location of spheroids on CAM surface was difficult in white light reflectance image due to colour and subtle spheroid configuration. Addition of Hyp and Hyp:LDL formulation and fluorescent light very well visualized the tumour spheroid position (Fig. 2). In all experimental groups Hyp exhibits gradual increase of fluorescence intensity through observation period predominantly in TE1 tumour spheroids, but also in healthy CAM tissue (Fig. 3, Fig. 4). Difference in fluorescence intensity between tumour spheroid and healthy tissue was significant at all times (at least $p<0.05)$, except free Hyp at time $0(p=0.18)$ (Fig. 3A). The largest difference in fluorescence intensity between the healthy and the tumour tissue was observed in Hyp:LDL group 6 hours after administration with slightly larger difference in Hyp:LDL 200:1. Free Hyp formulation, together with HYP:LDL 100:1 exhibited one hour after administration significantly lower tumour-normal difference in fluorescence intensity ( $p<0.001)$ (Fig. 4). After 6-hours Hyp:LDL formulations did not differ, however, free Hyp had still significantly lower tumour-normal difference in fluorescence intensity $(p<0.01)$ (Fig. 4). LDL-based transport system thus significantly potentiates tumour-normal difference in fluorescence intensity in observed time intervals. Comparison of fluorescence intensity in red spectral band of tumours only presents significantly higher intensity in both Hyp:LDL groups than in free Hyp at all times $(p<0.001)$ (Fig. 5). Hyp:LDL formulations did not differ, except 4 and 5 hours after administration, when 100:1 formulation had higher fluorescence intensity than 200:1 $(p<0.05$ and $p<0.01$, respectively).

Histological analysis of the CAM tissue with single TE1 spheroid or fusion of several spheroids showed vital cells which survived up to 5 days (data not shown). Four days after application, fused spheroids formed relatively large tumour (Fig. 6A) with radial spreading of infiltrative area clearly recognisable under Hyp fluorescence (Fig. 6B).

Survival of embryos in all experimental groups did not differ and no signs of toxicity (vasoconstriction, hemorrhage, lysis of vessels) were observed.

\section{Discussion}

Hyp photodynamic effectivity is related to its physicochemical properties, which are not fully favourable for medical administration. Hyp is a lipophilic compound, only sparingly soluble in water, which makes clinical application difficult.
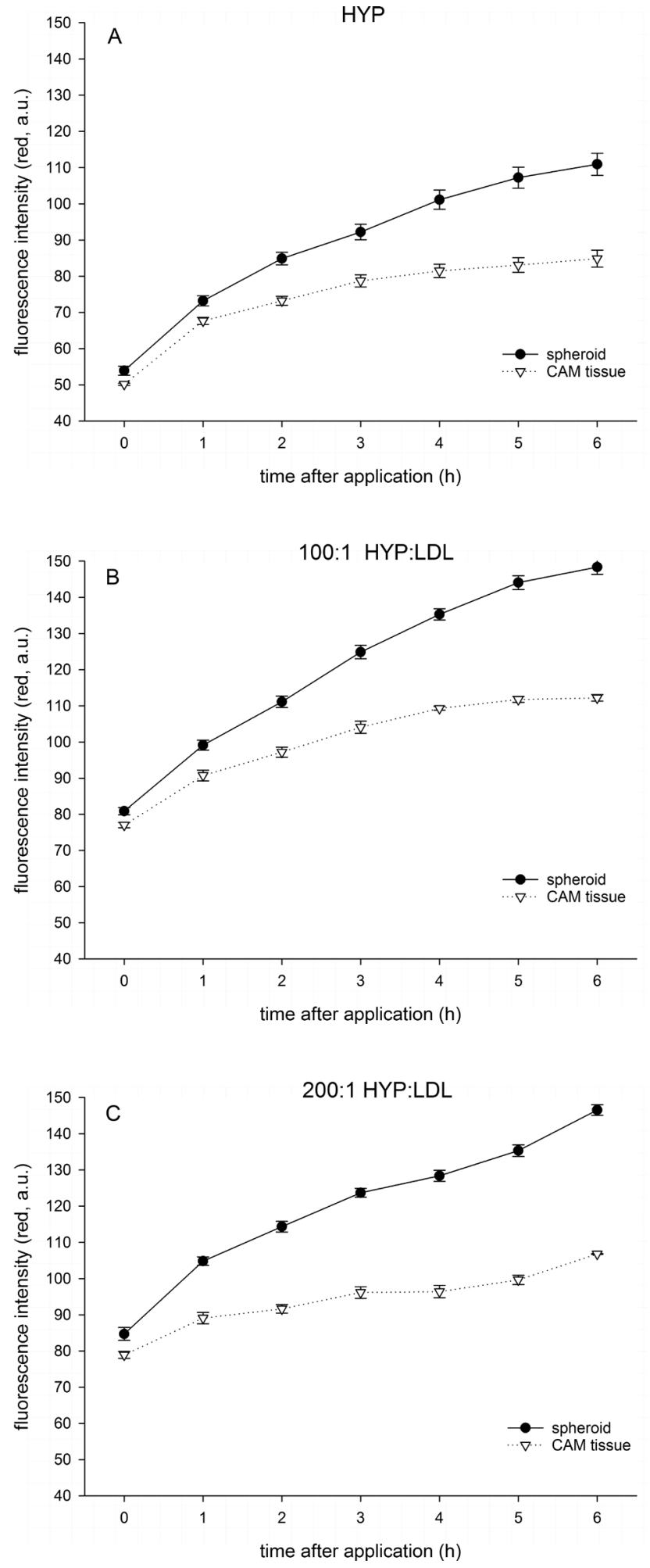

Figure 3. Fluorescence intensity (red channel) of healthy CAM tissue and TE1 tumour after application of Hyp (A), Hyp:LDL 100:1 (B) and 200:1 (C). Mean \pm SEM, $n=67\left(\mathrm{n}_{\text {group }}=25,22,20\right)$. Fluorescence intensity differed significantly (at least $p<0.05$ ) at all times, except Hyp at time $0(p=0.18)$. 


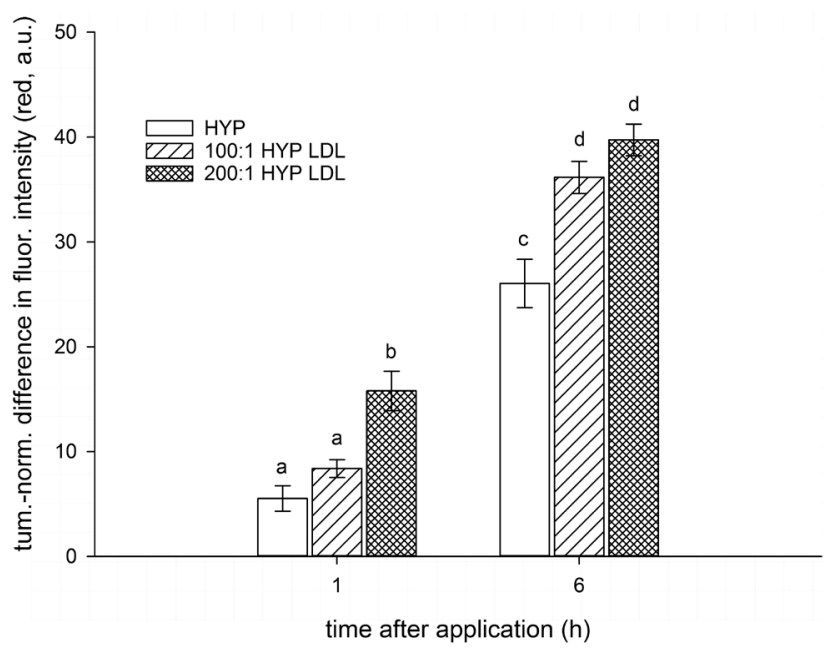

Figure 4. Difference in fluorescence intensity (red channel) between the healthy and tumour tissue measured 1 and 6 hours after application free Hyp, Hyp:LDL 100:1 and 200:1. Columns with different superscripts differ significantly (at least $p<0.05$ ).

Hyp in a polar water environment forms nonfluorescent aggregates. In this configuration Hyp exhibits hindered or completely inhibited photodynamic activity (Theodossiou et al. 2004; Bano et al. 2011; Wölfle et al. 2014). An indicator of biological activity of Hyp is fluorescence phenomenon. Only the monomeric form of Hyp exhibits fluorescence emission and so may participate in photodynamic reaction (Mikeš et al. 2011).

Different approaches have been taken to overcome the hydrophobicity of this photosensitizer. The solvents commonly

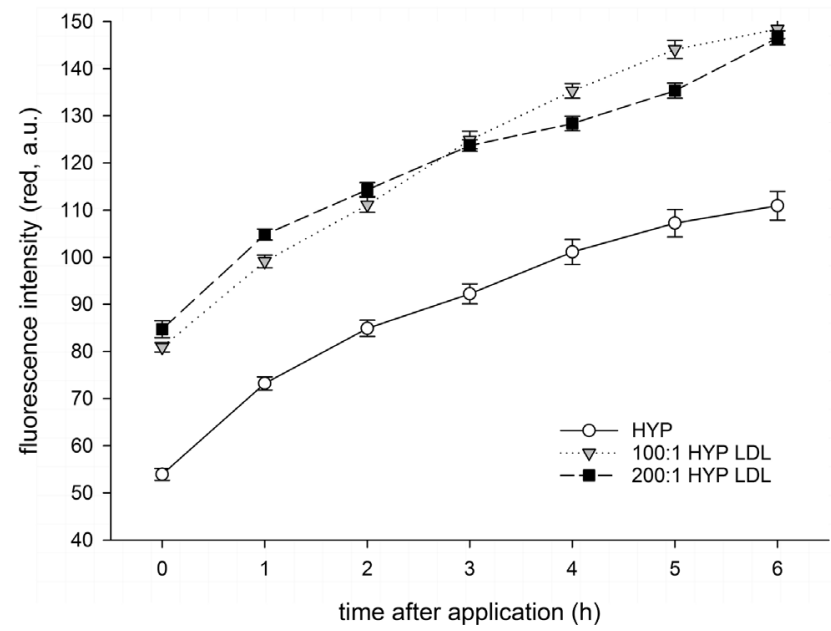

Figure 5. Increase in spheroid fluorescence intensity (red channel) after application of experimental formulations. Free Hyp had significantly lower fluorescence intensity at all times $(p<0.001)$. used to dissolve Hyp for in vitro and in vivo studies is DMSO and ethanol, alternatively glycerol, N-methylpyrrolidone, polyethylene glycol 400, or polyvinylpyrrolidone (Saw et al. 2006; Van de Putte et al. 2006). Currently, in Hyp-based fluorescence cystoscopy, the bladder instillation fluids are prepared with $1 \%$ plasma proteins. Fluorescence diagnosis of oral cancer was performed by oral rinsing with Hyp formulation prepared with $1 \%$ albumin (D'Hallewin et al. 2002; Saw et al. 2006; Thong et al. 2009). LDL appears to be promising delivery system for hydrophobic anti-tumour drugs and could play the key role for the specific targeting the photosensitizers into the tumour cells. LDL are recognized and internalized into the cells through specific membrane receptors, whose enhanced expression (regulated by the cholesterol needs of the cells) has been shown in many types of transformed cells (Kascakova et al. 2008).

In our experiments Hyp formulation has been initially analysed in vitro spectroscopically. Absorption spectrum Hyp:LDL present typical range of the Hyp max at 550 and $596 \mathrm{~nm}$. Absorbance spectral curves between Hyp:LDL complex 100:1 and 200:1 did not differ. On the other hand, free Hyp formulation in $0.1 \%$ DMSO presents strong reduction in absorbance which indicates dominant Hyp aggregation in this environment. Similar pattern changes of the emission spectrum were presented in other spectral analysis, where free Hyp itself exhibits very low fluorescence emission. Our results demonstrate Hyp:LDL complex produces a higher fluorescence intensity compared to Hyp alone. It appears that the aggregation of Hyp in the aqueous medium does not affect the incorporation of Hyp into LDL particles, therefore this transport system can provide higher grade of monomerization of this molecule and may be potentially suitable for PDD application.

There has been increasing interest in fluorescence-based techniques in clinical oncology, with the aim to detect and characterize premalignant and malignant lesions using in vivo fluorescence spectroscopy and imaging. The use of these techniques is considered for dosimetry in photodynamic therapy or to guide tissue biopsy and surgical resection (Wagnieres et al. 1998). Fluorescence diagnosis is used also for oral cancer detection as conventional white light endoscopy may fail to detect small and flat mucosal neoplasms (Olivo et al. 2011). Hyp-induced PDD by topical application was predominantly used for bladder and oral cancer detection. D'Hallewin et al. (2000) reported the clinical use of Hyp for detection of bladder flat CIS (carcinoma in situ) lesions, later for detection of bladder cancer (D'Hallewin et al. 2002; Kubin et al. 2008). Similar approach was used by Thong et al. (2009) who used oral rinsing with Hyp formulation as a complementary technique to white light endoscopy of human oral cancer. This may reduce the number of biopsies taken, improve detection of tumour margins during surgical procedures and provide a means for quick diagnosis in the 
A

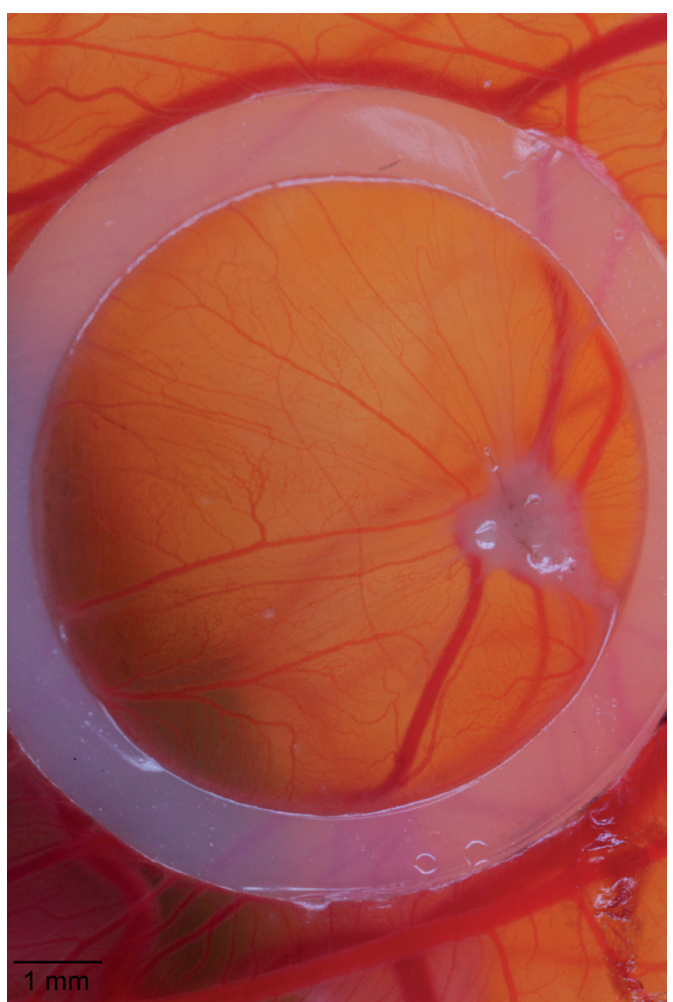

B

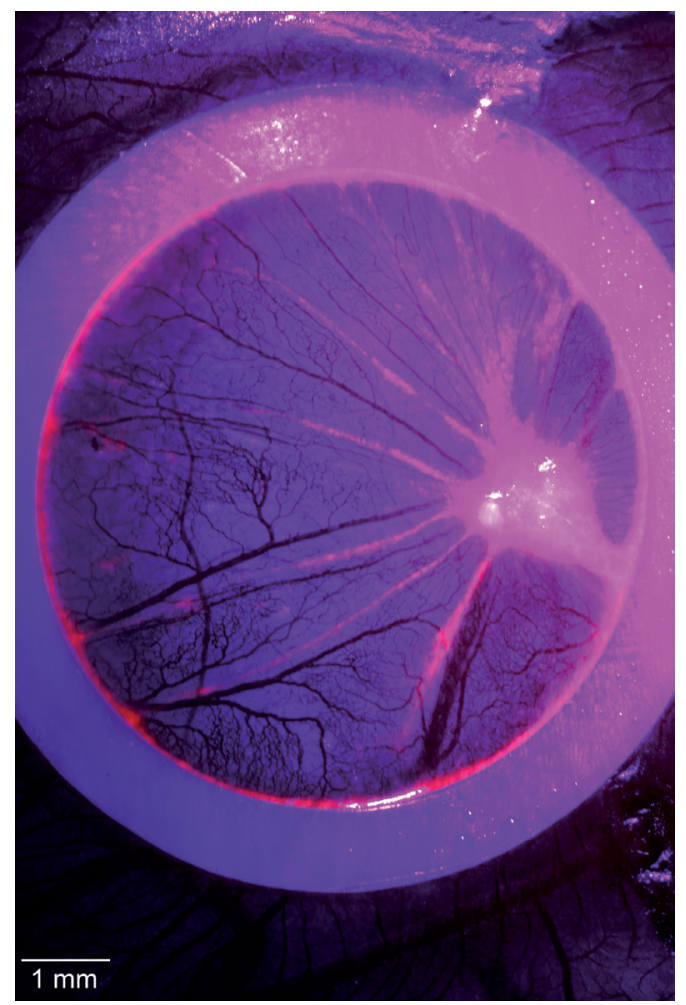

Figure 6. Advanced TE1 tumour in white light reflectance image (A) and in blue excitation light after application of Hyp:LDL 200:1 (B).

clinic (Thong et al. 2009). The sensitivity of PDD for detection of dysplasia was calculated to be $85 \%$ compared with $31 \%$ for white light endoscopy (Kubin et al. 2008).

Study of Hyp distribution in an orthotopic rat bladder tumour model showed tumour-to-normal-bladder ratio 12:1 after 4 hours of Hyp instillation (Kamuhabwa et al. 2002). In our experiments increased fluorescence was observed in TE1 tumour lesions, indicating a selective uptake of Hyp in lesions compared with normal tissue. In 6-hour observation period, TE1 spheroids exhibited gradual increase of fluorescence which was more intensive than in the healthy ectodermal epithelium. Overall increase of fluorescence is probably caused by gradual monomerization due to Hyp interaction with protein and lipidic structures of the tissue.

The cellular uptake of Hyp is thought to occur mainly by diffusion through concentration gradient, although a membrane-associated translocation with the assistance of albumin and/or LDL has also been suggested (Kiesslich et al. 2006). Our results indicate higher cellular uptake of Hyp with LDL transport system. Comparison of TE1 tumour fluorescence intensity revealed significantly higher intensity in both Hyp:LDL groups than in free Hyp formulation.

Properties of Hyp:LDL complex was studied by several authors. Buriankova et al. (2011) found that high Hyp:LDL ratios (>30:1) lead to a significant decrease of quantum yield of Hyp fluorescence. The decrease is caused by the formation of non-fluorescent Hyp aggregates inside of LDL molecules and by dynamic selfquenching of Hyp fluorescence. It was also shown that overloading LDL with Hyp (Hyp:LDL 200:1) leads to a higher intracellular accumulation of Hyp molecules in comparison with the situation when the same quantity of Hyp is accumulated in LDL, but at lower Hyp:LDL ratio (20:1) (Huntosova et al. 2010). Our results indicate that aggregation of the Hyp in the aqueous environment does not affect Hyp incorporation into LDL particles and Hyp:LDL formulation increases the efficiency of photodynamic diagnosis in the tissue after topical application. Hyp:LDL 200:1 achieved the highest tumour normal difference in fluorescence intensity, followed by Hyp:LDL 100:1, and free Hyp. LDL based transport system thus significantly potentiate tumour-normal difference in fluorescence intensity in observed time intervals.

Mechanisms of the preferential distribution of photosensitizers in tumour tissue are not fully understood. Properties of tumour tissue such as higher "leakiness" of vasculature, poorly developed lymphatic system and large interstitial space may contribute. Acidic $\mathrm{pH}$, elevated numbers of lowdensity protein receptors and a high amount of lipid (that has a high affinity for lipophilic dyes) also favors a preferential distribution of sensitizers (Musser et al. 1980; Freitas et al. 
1990; Kiesslich et al. 2006). Changes in expression of adhesion molecules in high grade advanced urothelial cell carcinoma (UCC) caused enhanced Hyp permeation into the deeper layers through passive paracellular transport before intracellular uptake (Olivo et al. 2012b).

In all experimental groups Hyp showed gradual increase of fluorescence intensity through 6-hour observation period in both healthy CAM and TE1 tumour spheroids. Location of spheroids on CAM surface in white light was often difficult, due to subtle spheroidal configuration. Both the free Hyp and Hyp:LDL complex formulation in the fluorescent image very well visualized the spheroid position, with fluorescence intensity peaking 6 hour after application.

Saw et al. (2007) showed on CAM model that Hyp-NMP formulation was a good alternative to the currently used $0.5 \%$ Hyp-HSA formulation. The NMP formulations were able to produce significantly higher contrast for tumour tissues and at earlier time points than Hyp-HSA 0.5\%. When properly formulated, Hyp can produce a good contrast between normal and tumour regions at earlier time point post drug administration. It has the potential to reduce patient's waiting time and resulting in improving patient quality of life (Saw et al. 2007).

On the other hand, in Francois et al. (2012) experimental study has been presented advantage of dendrimer based high molecular weight delivery system for topical photosensitizer application. Thus, the size of an intravesically-administered molecule appears to be essential to optimize tumour selectivity and depth of penetration into the tumour. Small molecules will tend to enter normal urothelium as well as the tumour, with loss of specificity (Francois et al. 2012).

In our experimental model LDL transportation system works in macromolecular configuration and exhibits clear superiority in fluorescence pharmacokinetics than free Hyp formulation. Disadvantage of higher molecular weight of this delivery system may be compensated by active transport through LDL-receptor complex and loss of intercellular adhesion and consequently enhanced paracellular transport of Hyp:LDL formulation in TE1 tumour spheroids tissue.

In summary, our experimental results confirm that the Hyp is strong fluorescent marker, prospectively applicable for photodynamic tumour diagnosis. LDL transport system appears to be a suitable model for optimizing the photodynamic diagnosis and therapy of cancer.

Acknowledgement. This work was supported by grants: APVV0242-11, VEGA 2/0102/15 and FP7 EU CELIM316310.

\section{References}

Abramoff M. D., Magelhaes P. J., Ram S. J. (2004): Image processing with ImageJ. Biophot. Int. 11, 36-42
Bano G., Stanicova J., Jancura D., Marek J., Bano M., Ulicny J., Strejckova A., Miskovsky P. (2011): On the diffusion of hypericin in dimethylsulfoxide/watermixtures-the effect of aggregation. J. Phys. Chem. B. 115, 2417-2423

http://dx.doi.org/10.1021/jp109661c

Betz C. S., Stepp H., Janda P., Arbogast S., Grevers G., Baumgartner R., Leunig A. (2002): A comparative study of normal inspection, autofluorescence and 5-ALA-induced PPIX fluorescence for oral cancer diagnosis. Int. J. Cancer 97, 245-252

http://dx.doi.org/10.1002/ijc.1596

Buriankova L., Buzova D., Chorvat Jr D., Sureau F., Brault D., Miskovsky P, Jancura D. (2011): Kinetics of hypericin association with low-density lipoproteins. Photochem. Photobiol. 87, 56-63 http://dx.doi.org/10.1111/j.1751-1097.2010.00847.x

Busch C., Krochmann J., Drews U. (2013): The chick embryo as an experimental system for melanoma cell invasion. PloS One 8, e53970 http://dx.doi.org/10.1371/journal.pone.0053970

Búzová D., Kasák P., Miškovský P., Jancura D. (2013): Solubilization of poorly soluble photosensitizer hypericin by polymeric micelles and polyethylene glycol. Gen. Physiol. Biophys. 32, 201-208

http://dx.doi.org/10.4149/gpb_2013023

Buzzá H. H., Silva L.V., Moriyama L.T., Bagnato V. S., Kurachi C. (2014): Evaluation of vascular effect of photodynamic therapy in chorioallantoic membrane using different photosensitizers. J. Photochem. Photobiol. B. 138, 1-7 http://dx.doi.org/10.1016/j.jphotobiol.2014.04.023

Čavarga I., Bilčík B., Výboh P., Záškvarová M., Chorvát D., Kasák P., Mlkvý P., Mateašík A., Chorvátová A., Miškovský P. (2014): Photodynamic effect of hypericin after topical application in the ex ovo quail chorioallantoic membrane model. Planta Med. 80, 56-62 http://dx.doi.org/10.1055/s-0033-1360174

Chouikrat R., Seve A., Vanderesse R., Benachour H., Barberi-Heyob M., Richeter S., Raehm L., Durand J. O., Verelst M., Frochot C. (2012): Non polymeric nanoparticles for photodynamic therapy applications: recent developments. Curr. Med. Chem. 19, 781-792 http://dx.doi.org/10.2174/092986712799034897

D'Hallewin M. A., De Witte P. A., Waelkens E., Merlevede W., Baert L. (2000): Fluorescence detection of flat bladder carcinoma in situ after intravesical instillation of hypericin. J. Urol. 164, 349-351

http://dx.doi.org/10.1016/S0022-5347(05)67357-0

D'Hallewin M. A., Kamuhabwa A. R., Roskams T., DeWitte P. A., Baert L. (2002): Hypericin-based fluorescence diagnosis of bladder carcinoma. BJU Int. 89, 760-763 http://dx.doi.org/10.1046/j.1464-410X.2002.02690.x

Debele T. A., Peng S., Tsai H. C. (2015): Drug carrier for photodynamic cancer therapy. Int. J. Mol. Sci. 16, 22094-22136 http://dx.doi.org/10.3390/ijms160922094

Esterbauer H., Gebicki J., Puhl H., Jürgens G. (1992): The role of lipid peroxidation and antioxidants in oxidative modification of LDL. Free Radic. Biol. Med. 13, 341-390 http://dx.doi.org/10.1016/0891-5849(92)90181-F

Evans C.L. (2015): Three-dimensional in vitro cancers spheroid models for photodynamic therapy: strengths and opportunities. Front. Phys. 3, 15 
http://dx.doi.org/10.3389/fphy.2015.00015

François A., Battah S., MacRobert A. J., Bezdetnaya L., Guillemin F., D'Hallewin M. A. (2012): Fluorescence diagnosis of bladder cancer: a novel in vivo approach using 5 -aminolevulinic acid (ALA) dendrimers. BJU Int. 110, 1155-1162 http://dx.doi.org/10.1111/j.1464-410X.2012.11407.x

Freitas I. (1990): Lipid accumulation: the common feature to photosensitizer retaining normal and malignant tissues. J. Photochem. Photobiol. B. 7, 359-361 http://dx.doi.org/10.1016/1011-1344(90)85169-W

Georges A., Wagnieres G. A., Star W. M., Wilson B. C. (1998): ln vivo fluorescence spectroscopy and imaging for oncological applications. Photochem. Photobiol. 68, 603-632 http://dx.doi.org/10.1111/j.1751-1097.1998.tb02521.x

Goldstein J. L., Brown M. S., Anderson R. G. W., Russell D. W., Schneider W. J. (1985): Receptor-mediated endocytosis: concepts emerging from the LDL receptor system. Ann. Rev. Cell. Biol. 1, 1-39 http://dx.doi.org/10.1146/annurev.cb.01.110185.000245

Huntosova V., Alvarez L., Bryndzova L., Nadova Z., Jancura D., Buriankova L., Bonneau S., Brault D., Miskovsky P., Sureau F. (2010): Interaction dynamics of hypericin with low-density lipoproteins and U-87 MG cells. Int. J. Pharm. 389, 32-40 http://dx.doi.org/10.1016/j.ijpharm.2010.01.010

Huygens A., Kamuhabwa A. R., Roskams T., van Cleynenbreugel B., van Poppel H., de Witte P. A. (2005): Permeation of hypericin in spheroids composed of different grade transitional cell carcinoma cell lines and normal human urothelial cells. J. Urol. 174, 69-72 http://dx.doi.org/10.1097/01.ju.0000162037.49102.56

Kamuhabwa A. A., Cosserat-Gerardin I., Didelon J., Notter D., Guillemin F., Roskams T., D’Hallewin M. A., Baert L., de Witte P. A. (2002): Biodistribution of hypericin in orthotopic transitional cell. Int. J. Cancer. 97, 253-260 http://dx.doi.org/10.1002/ijc.1594

Kascakova S., Nadova Z., Mateasik A., Mikes J., Huntosova V., Refregiers M., Sureau F., Maurizot J. C., Miskovsky P., Jancura D. (2008): High level of low-density lipoprotein receptors enhance hypericin uptake by U-87MG cells in the presence of LDL. Photochem. Photobiol. 84, 120-127

Kawczyk-Krupka A., Waśkowska J., Raczkowska-Siostrzonek A., Kościarz-Grzesiok A., Kwiatek S., Straszak D., Latos W., Koszowski R., Sieroń A. (2012): Comparison of cryotherapy and photodynamic therapy in treatment of oral leukoplakia. Photodiagnosis Photodyn. Ther. 9, 148-155 http://dx.doi.org/10.1016/j.pdpdt.2011.12.007

Kiesslich T., Krammer B., Plaetzer K. (2006): Cellular mechanisms and prospective applications of hypericin in photodynamic therapy. Curr. Med. Chem. 13, 2189-2204 http://dx.doi.org/10.2174/092986706777935267

Kubin A., Meissner P., Wierrani F., Burner U., Bodenteich A., Pytel A., Schmeller N. (2008): Fluorescence diagnosis of bladder cancer with new water soluble hypericin bound to polyvinylpyrrolidone: PVP-hypericin. Photochem. Photobiol. 84, 1560-1563 http://dx.doi.org/10.1111/j.1751-1097.2008.00384.x

Kunzi-Rapp K., Genze F., Kufer R., Reich E., Hautmann R. E., Gschwend J. E. (2001): Chorioallantoic membrane assay: vascularized 3-dimensional cell culture system for human prostate cancer cells as an animal substitute model. J. Urol. 166, 1502-1507 http://dx.doi.org/10.1016/S0022-5347(05)65820-X

Leunig A., Rick K., Stepp H., Gutmann R., Alwin G., Baumgartner R., Feyh J. (1996): Fluorescence imaging and spectroscopy of 5 aminolevulinic acid induced protoporphyrin IX for the detection of neoplastic lesions in the oral cavity. Am. J. Surg. 172, 674-677 http://dx.doi.org/10.1016/S0002-9610(96)00312-1

Liu M., Scanlon C. S., Banerjee R., Russo N., Inglehart R. C., Willis A. L., et al. (2013): The histone methyltransferase EZH2 mediates tumor progression on the chick chorioallantoic membrane assay, a novel model of head and neck squamous cell carcinoma. Transl. Oncol. 6, 273-281 http://dx.doi.org/10.1593/tlo.13175

Lokman N. A., Elder A. S., Ricciardelli C., Oehler M. K. (2012): Chick chorioallantoic membrane (CAM) assay as an in vivo model to study the effect of newly identified molecules on ovarian cancer invasion and metastasis. Int. J. Mol. Sci. 13, 9959-9970 http://dx.doi.org/10.3390/ijms13089959

Mikeš J., Hýždalová M., Kočí L., Jendželovský R., Koval'J., Vaculová A., Hofmanová J., Kozubík A., Fedoročko P. (2011): Lower sensitivity of FHC fetal colon epithelial cells to photodynamic therapy compared to HT-29 colon adenocarcinoma cells despite higher intracellular accumulation of hypericin. Photochem. Photobiol. Sci. 10, 626-632 http://dx.doi.org/10.1039/c0pp00359j

Miskovsky P. (2002): Hypericin - a new antiviral and antitumor photosensitizer: mechanism of action and interaction with biological molecules. Curr. Drug Targets 3, 55-84 http://dx.doi.org/10.2174/1389450023348091

Musser D. A., Wagner J. M., Weber F. J., Datta-Gupta N. (1980): The binding of tumor localizing porphyrins to a fibrin matrix and their effects following photoirradiation. Res. Commun. Chem. Pathol. Pharmacol. 28, 505-525

Neville B. W., Day T. A. (2002): Oral cancer and precancerous lesions. CA Cancer J. Clin. 52, 195-215 http://dx.doi.org/10.3322/canjclin.52.4.195

Nikanjam M., Blakely E. A., Bjornstad K. A., Shu X., Budinger T. F., Forte T. M. (2007): Synthetic nano-low density lipoprotein as targeted drug delivery vehicle for glioblastoma multiforme. Int. J. Pharm. 328, 86-94 http://dx.doi.org/10.1016/j.ijpharm.2006.07.046

Nowak-Sliwinska P., Segura T., Iruela-Arispe M. L. (2014): The chicken chorioallantoic membrane model in biology, medicine and bioengineering. Angiogenesis 17, 779-804 http://dx.doi.org/10.1007/s10456-014-9440-7

Olivo M., Bhuvaneswari R., Keogh I. (2011): Advances in biooptical imaging for the diagnosis of early oral cancer. Pharmaceutics 3, 354-378 http://dx.doi.org/10.3390/pharmaceutics3030354

Olivo M., Fu C. Y., Raghvan V., Lau W. K. (2012a): New frontier in hypericin-mediated diagnosis of cancer with current optical technologies. Ann. Biomed. Eng. 40, 460-473 http://dx.doi.org/10.1007/s10439-011-0462-7

Olivo M., Lucky S. S., Kent Mancer J. F., Lau W. K. (2012 b): Altered expression of cell adhesion molecules leads to differential uptake of hypericin in urothelial cancer. Urol. Oncol. 30, 624-634 
http://dx.doi.org/10.1016/j.urolonc.2010.07.006

Parsons-Wingerter P., Elliott K. E., Farr A. G., Radhakrishnan K., Clark J. I., Sage E. H. (2000): Generational analysis reveals that TGF-betal inhibits the rate of angiogenesis in vivo by selective decrease in the number of new vessels. Microvasc. Res. 59, 221-232 http://dx.doi.org/10.1006/mvre.1999.2213

Rowe R. G., Li X. Y., Hu Y., Saunders T. L., Virtanen I., Garcia de Herreros A., Becker K. F., Ingvarsen S., Engelholm L. H., Bommer G. T., Fearon E. R., Weis S. J. (2009): Mesenchymal cells reactivate Snaill expression to drive three-dimensional invasion programs. J. Cell. Biol. 184, 399-408 http://dx.doi.org/10.1083/jcb.200810113

Saw C. L., Olivo M., Soo K. C., Heng P. W. (2006): Delivery of hypericin for photodynamic applications. Cancer Lett. 241, 23-30 http://dx.doi.org/10.1016/j.canlet.2005.10.020

Saw C. L., Olivo M., Chin W. W., Soo K. C., Heng P. W. (2007): Superiority of N-methylpyrrolidone over albumin with hypericin for fluorescence diagnosis of human bladder cancer cells implanted in the chick chorioallantoic membrane model. J. Photochem. Photobiol. B. 86, 207-218 http://dx.doi.org/10.1016/j.jphotobiol.2006.10.003

Siboni G., Weitman H., Freeman D., Mazur Y., Malik Z., Ehrenberg B. (2002): The correlation between hydrophilicity of hypericins and helianthrone: internalization mechanisms, subcellular distribution and photodynamic action in colon carcinoma cells. Photochem. Photobiol. Sci. 1, 483-491 http://dx.doi.org/10.1039/b202884k

Theodossiou T., Spiro M. D., Jacobson J., Hothersall J. S., Macrobert A. J. (2004): Evidence for intracellular aggregation of hypericin and the impact on its photocytotoxicity in PAM 212 murine keratinocytes. Photochem. Photobiol. 80, 438-443 http://dx.doi.org/10.1562/0031-8655(2004)080<0438:EFIA$\mathrm{OH}>2.0 . \mathrm{CO} ; 2$

Thomas C., Pardini R. S., (1992): Oxygen dependence of hypericininduced phototoxicity to EMT6 mouse mammary carcinoma cells. Photochem. Photobiol. 55, 831-837 http://dx.doi.org/10.1111/j.1751-1097.1992.tb08531.x

Thong P. S., Olivo M., Chin W. W., Bhuvaneswari R., Mancer K., Soo K. C. (2009): Clinical application of fluorescence endoscopic imaging using hypericin for the diagnosis of human oral cavity lesions. Br. J. Cancer. 101, 1580-1584 http://dx.doi.org/10.1038/sj.bjc.6605357

Van de Putte M., Roskams T., Vandenheede J. R., Agostinis P., de Witte P. A. (2005): Elucidation of the tumoritropic principle of hypericin. Br. J. Cancer 92, 1406-1413 http://dx.doi.org/10.1038/sj.bjc.6602512

Vargas A., Zeisser-Labouebe M., Lange N., Gurny R., Delie F. (2007): The chick embryo and its chorioallantoic membrane (CAM) for the in vivo evaluation of drug delivery systems. Adv. Drug Deliv. Rev. 30, 1162-1176 http://dx.doi.org/10.1016/j.addr.2007.04.019

Wagnieres G. A., Star W. M., Wilson B. C. (1998): In vivo fluorescence spectroscopy and imaging for oncological applications. Photochem. Photobiol. 68, 603-632 http://dx.doi.org/10.1111/j.1751-1097.1998.tb02521.x

Wölfle U., Seelinger G., Schempp C. M. (2014): Topical application of St. John's wort (Hypericum perforatum). Planta Med. 80, 109-120

Xiao X., Zhou X., Ming H., Zhang J., Huang G., Zhang Z., Li P. (2015): Chick Chorioallantoic Membrane Assay: A 3D animal model for study of human nasopharyngeal carcinoma. PLoS One 10, e0130935 http://dx.doi.org/10.1371/journal.pone.0130935

Zheng W., Olivo M., Soo K. C. (2004): The use of digitized endoscopic imaging of 5-ALA-induced PPIX fluorescence to detect and diagnose oral premalignant and malignant lesions in vivo. Int. J. Cancer 110, 295-300

http://dx.doi.org/10.1002/ijc.20080

Received: February 10, 2016

Final version accepted: April 5, 2016

First published online: July 22, 2016 